University of Nebraska - Lincoln

DigitalCommons@University of Nebraska - Lincoln

Public Health Resources

Public Health Resources

1995

\title{
Fulminant Hepatic Failure: Summary of a Workshop
}

\author{
Jay Hoofnagle \\ National Institutes of Health, hoofnaglej@mail.nih.gov \\ Robert Carithers Jr. \\ University of Washington Medical Center \\ Craig Shapiro \\ Centers for Disease Control and Prevention \\ Nancy Ascher \\ University of California - San Francisco, nancy.ascher@ucsfmedctr.org
}

Follow this and additional works at: https://digitalcommons.unl.edu/publichealthresources

Part of the Public Health Commons

Hoofnagle, Jay; Carithers, Robert Jr.; Shapiro, Craig; and Ascher, Nancy, "Fulminant Hepatic Failure: Summary of a Workshop" (1995). Public Health Resources. 254.

https://digitalcommons.unl.edu/publichealthresources/254

This Article is brought to you for free and open access by the Public Health Resources at DigitalCommons@University of Nebraska - Lincoln. It has been accepted for inclusion in Public Health Resources by an authorized administrator of DigitalCommons@University of Nebraska - Lincoln. 


\title{
Fulminant Hepatic Failure: Summary of a Workshop
}

\author{
Jay H. Hoofnagle, ${ }^{1}$ Robert L. Carithers, $\mathrm{JR}^{2}{ }^{2}$ Craig Shapiro, ${ }^{3}$ And Nancy Ascher ${ }^{4}$
}

Fulminant hepatic failure (FHF) is defined by the appearance of severe liver injury with hepatic encephalopathy in a previously healthy person. There are an estimated 2,000 cases of FHF in the United States yearly, representing $0.1 \%$ of all deaths and, perhaps, $6 \%$ of liverrelated deaths. The causes of FHF are many, the chief ones in the United States being hepatitis A; B; non-A, non-B and drug induced liver disease. There are no specific therapies for FHF, however, liver transplantation is recommended for situations in which spontaneous recovery appears unlikely. Factors that are valuable in assessing the likelihood of spontaneous recovery are static features such as patient age and etiology of FHF and dynamic features including encephalopathy grade, prothrombin time, and serum bilirubin. Presently, approximately $7 \%$ of all liver transplants are done for FHF and the 1-year patient survival rates average $63 \%$, somewhat less than survival rates for nonfulminant liver disease, averaging $78 \%$. The management of patients with FHF is challenging, particularly important being monitoring and early treatment of infections, hemodynamic abnormalities, and brain edema. Innovative approaches to management and therapy include use of cytoprotective or antiviral medications, hepatic support systems, extracorporeal liver support, hepatocyte transplanta-

Abbreviations: FHF, fulminant hepatic failure; OLTx, orthotopic liver transplantation; UCSF, University of California, San Francisco; HCV, hepatitis $\mathrm{C}$ virus; anti-HCV, antibody to $\mathrm{HCV}$; $\mathrm{HBV}$, hepatitis B virus; HBsAg, hepatitis B surface antigen; HBeAg, hepatitis B e antigen; HEV, hepatitis E virus; CDC, Centers for Disease Control and Prevention; VHSP, Viral Hepatitis Surveillance Program; NCHS, National Center for Health Statistics; ICD-9, International Classification of Diseases-9th Revision; UNOS, United Network for Organ Sharing; NIDDK, National Institute of Diabetes and Digestive and Kidney Diseases; CI, confidence interval; CPP, cerebral perfusion pressure; ICP, intracerebral pressures; CSF, cerebrospinal fluid; ATPase, adenosine triphosphatase; CT, computed tomography; ALT, alanine transaminase; LDL, low-density lipoprotein; mRNA, messenger RNA; PGE, prostaglandin E; ECL, extracorpeal liver; Ig, immunoglobulin.

From the ${ }^{1}$ Division of Digestive Diseases and Nutrition, National Institute of Diabetes and Digestive and Kidney Diseases, National Institutes of Health, Bethesda, MD; ' Department of Medicine, University of Washington Medical Center, Seattle, WA; ${ }^{3}$ Hepatitis Branch, Centers for Disease Control and Prevention, Atlanta, GA; and ${ }^{4}$ Liver Transplant Service, University of California at San Francisco, San Francisco, CA.

Received November 22, 1993; accepted June 28, 1994.

Sponsored by Digestive Diseases Advisory Board, February 1-2, 1993, Chantilly, VA.

Address reprint requests to: Jay $H$. Hoofnagle, MD, Building 31, Room 9A23, National Institutes of Health, Bethesda, MD 20892

Copyright 1995 by the American Association for the Study of Liver Diseases.

$0270-9139 / 95 / 2101-0036 \$ 3.00 / 0$ tion, auxiliary liver transplantation, and xenotransplantation. None of these are of proven benefit, but many are promising as a means to support the patient with FHF until spontaneous recovery occurs or a suitable liver graft is available for transplantation. (HEPATOLOGY $1995 ; 21: 240-252$.)

Fulminant hepatic failure (FHF) is one of the more dramatic and challenging syndromes in clinical medicine. At present, there are no universally accepted criteria for the diagnosis of FHF. For practical purposes, FHF is defined by the appearance of severe acute liver disease with hepatic encephalopathy in a previously healthy person. ${ }^{1}$ Hepatic failure is often referred to as subfulminant if onset of encephalopathy occurs more than 8 weeks after onset of jaundice. FHF represents a clinical syndrome rather than a specific disease and can be caused by a variety of viruses, drugs, toxins, and metabolic disorders.

The mortality rate of FHF is high, and there is no effective therapy for any of its major causes. Nonetheless, medical therapy is critical in dealing with the many complications of FHF, including bacterial and fungal infections, hemodynamic instability, brain edema, renal and pulmonary failure, acid-base and electrolyte disturbances, and coagulopathy. Orthotopic liver transplantation (OLTx) has been used increasingly as an alternative to conservative medical management in patients with FHF in whom spontaneous survival is deemed to be unlikely. Critical in the decision to use OLTx is the assessment of the likelihood of spontaneous recovery. OLTx commits the patient to a life-long need for immunosuppression to prevent graft rejection. The timing of OLTx in patients with FHF also is critical; a donor liver is often needed rapidly, and any delay can result in appearance of severe infectious complications or permanent neurological damage. Finally, long-term survival after OLTx for FHF has been relatively poor in comparison with survival after OLTx for other conditions. These considerations make the role of OLTx in management of FHF particularly challenging and controversial. New and better means of management are needed.

On February 1 to 2, 1993, the National Digestive Diseases Advisory Board sponsored a workshop entitled "Current Issues in the Management of Fulminant Hepatic Failure" to address recommendations for the 
TABLE 1. Etiology of 60 Cases of FHF: UCSF

\begin{tabular}{lc}
\hline \multicolumn{1}{c}{ Etiology } & No. (\%) \\
\hline Hepatitis A & $5(8 \%)$ \\
Hepatitis B & $9(\mathbf{1 5 \% )}$ \\
Hepatitis C & 0 \\
Hepatitis non-A, B, or C & $23(38 \%)$ \\
Acetaminophen & $11(18 \%)$ \\
Toxins or drugs & $9(\mathbf{1 5 \% )}$ \\
Miscellaneous & $3(5 \%)$ \\
\hline
\end{tabular}

current medical management of this condition, the role of OLTx, and the role of new and evolving innovative approaches in this challenging clinical condition.

\section{CAUSES OF FHF IN THE UNITED STATES}

The causes of FHF in the United States were discussed by Dr Teresa Wright (Department of Medicine, Veterans Affairs Medical Center and University of California, San Francisco, CA [UCSF]). FHF can be caused by viruses, drugs, toxins, and miscellaneous conditions, including Wilson's disease, Budd-Chiari syndrome, ischemia, and hyperthermia. ${ }^{1}$ Identifying the cause of FHF in individual cases is important because of implications for prognosis, therapy, and prevention. Diagnosis requires application of intensive epidemiological, clinical and serological methods. The results of analysis of a cohort of 60 cases of FHF referred to UCSF between 1989 and 1992 are shown in Table 1.

In this series and in others, hepatitis A and B were the most frequently identified viruses causing $\mathrm{FHF}^{2}$ Although no cases were identified in this series, hepatitis $D$ and $E$ account for a variable but usually small proportion of cases of FHF in Western countries. Most striking, however, was that hepatitis $\mathrm{C}$ did not account for a single case, despite the use of sensitive serological tests for hepatitis $\mathrm{C}$ virus (HCV) RNA as well as antibody to HCV (anti-HCV). This low rate of fulminant hepatitis $\mathrm{C}$ has been found by others: in a recent summary of four studies using tests for anti-HCV and HCV RNA, hepatitis $\mathrm{C}$ accounted for only $2 \%$ of cases of FHF (2 of 81 patients). ${ }^{2}$ Occasionally, chronic HCV infection appeared to be a cofactor with acute hepatitis $\mathrm{B}$ in causing $\mathrm{FHF}^{3}{ }^{3}$

These findings, as well as results from other investigators, indicate that the single most common etiology of FHF is unknown. FHF can also be caused by other nonhepatotropic viruses, such as Epstein-Barr virus, cytomegalovirus, adenoviruses, and herpes simplex virus, but these are exceedingly rare causes of FHF and usually present with distinctive clinical features. Preliminary findings suggesting that a paramyxovirus may account for some cases, especially those associated with giant-cell formation, remain unconfirmed. ${ }^{4}$ Thus, most FHF in the United States is best described simply as cryptogenic.

Some cases of cryptogenic FHF may actually be caused by hepatitis B. Mutations in critical hepatitis $B$ virus (HBV) genes may cause a mutant virus that produces infection and disease but not hepatitis B surface antigens ( $\mathrm{HBsAg}$ ) or hepatitis $\mathrm{B}$ e antigens (HBeAg). For instance, the well-described HBeAg-negative mutant of $\mathrm{HBV}$, which has a mutation in the precore region that blocks synthesis of $\mathrm{HBeAg}$, has been linked to FHF in several areas of the world. Omata et $\mathrm{al}^{5}$ found precore mutations in seven of seven Japanese patients with fulminant hepatitis B. Similarly, Liang et $\mathrm{al}^{6}$ found precore mutants in all five patients with FHF in an outbreak of hepatitis B in Israel. In Western countries, the precore mutant appears to be less important as a cause of FHF. ${ }^{7}$ Furthermore, it is not clear whether the precore mutant actually predisposes patients to more severe hepatitis or whether these reports represent peculiar outbreaks.

HBV mutants with defects in the HBsAg gene also have been described and may account for some cases of cryptogenic $\mathrm{FHF}^{8,9}$ A number of investigators have found HBV DNA by Southern blot analysis in livers of HBsAg-negative patients with FHF. HBsAg was not detected in serum of these patients before OLTx, but the patients became positive for it after transplantation. The role that these cryptic cases of hepatitis B play in the overall prevalence of FHF deserves further evaluation.

Hepatitis $\mathrm{E}$ virus (HEV) infection is another potential cause of FHF that might be missed by conventional serological testing. Hepatitis $\mathrm{E}$ can lead to $\mathrm{FHF}$, particularly in pregnant women. The methodology for diagnosis of hepatitis $\mathrm{E}$ is still problematic. Among five studies from Western countries, hepatitis $\mathrm{E}$ was identified in only two studies, and it accounted for only 6 of $97(6 \%)$ total cases. ${ }^{2}$

Many drugs are capable of inducing FHF, and some cases of cryptogenic disease may be caused by exposure to a medication or toxin in the environment that is not considered significant or is not recognized or remembered by the patient. Careful toxicological screening may help detect some of these cases. Less common causes of FHF include Wilson's disease, shock or ischemia, hyperthermia, hypothermia, Budd-Chiari syndrome, malignancy, and the microsteatosis syndromes of fatty liver of pregnancy, Reye's syndrome, and druginduced steatosis. The differential diagnosis of $\mathrm{FHF}$ should lead to careful search for causes before the term cryptogenic is applied.

However, despite intensive analysis and use of the most modern techniques, the cause of most cases of FHF remains unknown. This finding calls for further intensive research, using animal models as well as the most innovative molecular techniques, to help define and eventually prevent or treat these unknown but important causes of $\mathrm{FHF}$.

\section{EPIDEMIOLOGY}

The epidemiology of FHF in the United States was discussed by Dr Craig Shapiro (Medical Epidemiologist, Hepatitis Branch, Centers for Disease Control and Prevention [CDC], Atlanta, GA). The most comprehensive system with data on the mortality from acute hepa- 
TABLE 2. Estimated Deaths Caused by Acute Viral Hepatitis, United States

\begin{tabular}{lccc}
\hline \multicolumn{1}{c}{ Type } & $\begin{array}{c}\text { Case } \\
\text { Fatality }\end{array}$ & $\begin{array}{c}\text { Estimated No. } \\
\text { of Icteric Cases }\end{array}$ & $\begin{array}{c}\text { Estimated } \\
\text { No. of Deaths }\end{array}$ \\
\hline Hepatitis A & $0.2 \%-0.4 \%$ & 75,000 & $120-304$ \\
Hepatitis B & $1.0 \%-1.2 \%$ & 100,000 & $950-1,220$ \\
Non-A, non-B & $1.5 \%-2.5 \%$ & 37,500 & $570-950$ \\
Total & & 212,500 & $1,640-2,474$ \\
\hline
\end{tabular}

titis and the incidence of hepatitis in the United States is the Viral Hepatitis Surveillance Program (VHSP), a nationwide system operated by the CDC that provides demographic, diagnostic, risk factor, and outcome information on reported cases of acute viral hepatitis. Between 1983 and 1989, 169,666 cases of acute hepatitis were reported to the VHSP, of which $1,565(.9 \%)$ were fatal. ${ }^{10}$ The fatality rate was lowest for hepatitis A $(328$ of $80,689,0.4 \%)$, intermediate for hepatitis B $(948$ of $77,490,1.2 \%)$ and highest for non-A, non-B hepatitis ( 289 of $11,487,2.5 \%$ ). Age-specific rates indicated that mortality was higher in patients 50 years of age or older and in those younger than 5 years of age for all forms of hepatitis. Because this system relies on passive surveillance, reporting of cases is incomplete, and severe cases (including deaths) may be more likely to be reported than milder cases. Therefore, the calculated fatality rates may be high.

More accurate but geographically limited data on the incidence and mortality of acute viral hepatitis is available from the Sentinel Counties Study, an intensive surveillance system for all cases of viral hepatitis in four counties in the United States. ${ }^{11,12}$ In this system, patients with acute hepatitis are interviewed by trained personnel, and serum samples are obtained for special serological testing. Thus, more accurate demographic characterization and diagnosis are possible. This important study has provided key information on the epidemiology, mode of transmission, pathogenesis, and natural history of acute and chronic viral hepatitis in the United States. Between 1982 and 1990, 11,226 cases of acute hepatitis, of which 88 were fatal $(0.8 \%)$, were entered into the Sentinel Counties Study. The mortality rate was $0.2 \%$ for hepatitis A (7 of 4,251 cases), $1 \%$ for hepatitis B ( 42 of 4,410 cases), and $1.5 \%$ for non-A, non-B hepatitis (39 of 2,565 cases).

The application of the case-fatality rates obtained from VHSP and the Sentinel Counties Study to the estimated annual number of cases of icteric hepatitis in the United States suggests that there are approximately 2,000 deaths from acute viral hepatitis yearly (Table 2).

Because FHF has causes other than acute hepatitis, surveillance systems have limitations in making inferences about the incidence of FHF. Two other systems can be used to assess mortality and morbidity of FHF: multiple cause of death data and the National Hospital Discharge Survey, both from the National Center for Health Statistics (NCHS). ${ }^{13,14}$
TABLE 3. Number of Cases of OLTx for FHF by Year in the United States

\begin{tabular}{lrrrr}
\hline \multicolumn{1}{c}{ Year } & $\mathbf{1 9 8 8}$ & $\mathbf{1 9 8 9}$ & $\mathbf{1 9 9 0}$ & $\mathbf{1 9 9 1}$ \\
\hline Total no. of OLTx & 1,488 & 1,853 & 2,307 & 2,574 \\
No. OLTx for FHF $(\%)$ & 110 & 126 & 167 & 149 \\
& $(7.4 \%)$ & $(6.8 \%)$ & $(7.2 \%)$ & $(5.8 \%)$ \\
\hline
\end{tabular}

There are approximately 2 million deaths per year in the United States. Information on the major cause of death and on up to 20 contributing causes is included on all death certificates. There are no International Classification of Diseases-9th Revision, (ICD-9) codes specific for FHF. Using hepatic coma without mention of chronic liver disease, alcoholism, or neoplasm as an associated condition as a means of capturing cases, approximately 7,489 deaths from FHF could be identified between 1980 and 1988, an incidence of 3.5 deaths caused by FHF per million people. Rates were higher for men than women and for blacks than whites.

Statistics from the National Hospital Discharge Survey include detailed information on discharge diagnoses from 500 hospitals in the United States. Between 1988 and 1990 there were an estimated 23,103 total hospital discharges coded as hepatic coma without mention of chronic liver disease, alcoholism, or neoplasm. This estimate converts to a rate of 31.2 hospitalizations for FHF per million people. The average hospital stay for this diagnosis was 17.5 days, yielding an estimated 135,000 hospital days per year. As with death certificate information, the rate of hospitalization for this diagnosis was higher in blacks than whites but was equal in men and women.

Obviously, better information on the epidemiology and incidence of FHF is needed. The current reporting systems suggest that there are approximately 2,000 deaths from FHF related to viral hepatitis yearly, which would represent approximately $0.1 \%$ of all deaths and perhaps $6 \%$ of liver-related deaths.

\section{CURRENT STATUS OF LIVER TRANSPLANTATION FOR FHF}

The current use of OLTx for FHF in the United States was reviewed by Dr Katherine Detre (Professor of Epidemiology, Graduate School of Public Health, University of Pittsburgh, Pittsburgh, PA). Information was obtained from the United Network for Organ Sharing (UNOS), which collects a limited amount of information on all transplantations performed in the United States. ${ }^{15}$ Supportive data is also available for the $\mathrm{Na}$ tional Institute of Diabetes and Digestive and Kidney Diseases (NIDDK) Liver Transplantation Database. ${ }^{16}$ According to information from UNOS, FHF accounts for approximately 7\% of OLTx performed (Table 3).

This indication for transplantation was more frequent for children (11\% to $13 \%$ ) than for adults (6\% to $7 \%$ ). Overall, the median age of persons who received transplants for FHF (28 years) was lower than the me- 
TABLE 4. Etiology of FHF in Patients Undergoing OLTx

\begin{tabular}{lcr}
\hline \multicolumn{1}{c}{ Etiology } & $\begin{array}{c}\text { Children } \\
(\mathbf{n = 1 4 6 )}\end{array}$ & $\begin{array}{c}\text { Adults } \\
(\mathbf{n = 4 2 4 )}\end{array}$ \\
\hline Not specified & $47.3 \%$ & $25.9 \%$ \\
Hepatitis A & $10.3 \%$ & $6.6 \%$ \\
Hepatitis B & $4.1 \%$ & $23.4 \%$ \\
Hepatitis C & - & $3.8 \%$ \\
Non-A, non-B hepatitis & $26.7 \%$ & $22.6 \%$ \\
Drug-induced injury & $9.6 \%$ & $\mathbf{1 6 . 0 \%}$ \\
Other & $2.1 \%$ & $1.7 \%$ \\
\hline
\end{tabular}

dian age for people who received transplants for other causes (44 years), this differential holding true even when adults were analyzed separately. FHF was a more frequent indication for OLTx for minority groups than it was for whites.

The major cause of FHF leading to OLTx was unknown ("not otherwise specified"), followed by "non-A, non-B" hepatitis, hepatitis B, drugs, and hepatitis A (Table 4). Acetaminophen overdose or toxicity accounted for $2 \%$ of FHF cases in children and for $5 \%$ in adults.

FHF patients undergoing OLTx were more likely to be on life support than were those undergoing transplantation for nonfulminant diseases $(60 \%$ vs. $10 \%$ in adults), and the waiting time for transplantation was considerably shorter (mean, 5.3 days vs. 60.4 days in adults; 7.5 days vs. 106.1 days in children). Patients with FHF received liver transplants from donors with similar characteristics (age, cause of death, and so on), except for children, who were more likely to receive a liver from an older donor if they had FHF. More importantly, however, patients with FHF were more likely to receive an incompatible blood group system (ABO)-matched donor (11\% vs. $1.9 \%$ in adults; $17.7 \%$ vs. $5.7 \%$ in children). Finally, patients with FHF had lower rates of patient and graft survival than patients with nonfulminant disease (Table 5).

The relative risk for survival for 1 year for cases that received transplants for FHF was 1.89 (95\% confidence interval $[\mathrm{CI}]=1.66-2.15)$ for graft failure and $1.91(95 \%$ $\mathrm{CI}=1.65-2.21$ ) for death indicating worse prognosis for OLTx for FHF than for other causes. However, when risk was adjusted for multiple factors that differed between patients with FHF and those with other causes for OLTx, the relative risk decreased to approximately 1.00 for both 1-year graft and patient survival. The most important factor was the recipient functional status, especially the need for life support. Age of the patient, donor age, cause of $\mathrm{FHF}$, and pretransplantation laboratory values did not appear to correlate with poor outcome. Thus, survival after OLTx for FHF was not different than it was for other indications when the clinical condition of the patient was considered.

\section{PROGNOSTIC FEATURES IN FHF}

The decision to perform OLTx for a patient with FHF must take three questions into consideration: (1) Is spontaneous recovery probable? (2) If not, is transplantation feasible? (3) Or, have irretrievable complications occurred?

Spontaneous recovery is certainly the preferable outcome in FHF because most patients are left with no residual liver disease, and thus they avoid the risk and expense of the transplantation itself and the lifelong immunosuppressive therapy. On the other hand, recovery from FHF may not be possible, in which case urgent OLTx is the only option. Timing is critical to successful transplantation; if OLTx is performed too early, it may not have been necessary; if it was performed too late, the patient with FHF may have already developed severe neurological damage or a life-threatening infection. The critical decision of when to perform OLTx requires knowledge of accurate and sensitive prognostic factors for determining the likelihood of spontaneous recovery.

Predictive factors for survival in FHF were outlined by Robert L. Carithers, Jr, MD, (Department of Medicine, University of Washington, Seattle, WA). Prognostic factors for survival in FHF have been extensively analyzed in large series of patients from Boston, ${ }^{17}$ Los Angeles ${ }^{18}$ Paris, ${ }^{19}$ and London. ${ }^{20,21}$ From these studies, two types of clinical variables have been identified as helpful in assessing prognosis: static variables, which are present at the time of admission and do not change (such as patient age, race, gender, and cause of disease), and dynamic variables, which do change during the course of illness (such as degree of coma, serum bilirubin, and prothrombin time).

Static variables that have been found to correlate with survival from FHF are patient age and etiology. Survival rate in patients between the ages of 10 and 40 years is between $30 \%$ and $35 \%$, whereas survival rate in patients older than 40 years of age or younger than 10 years of age is poor, less than $10 \% .{ }^{17-21}$ Patients with hepatitis $A$ and acetaminophen toxicity have the highest survival rate; those with hepatitis B and D have intermediate survival rates; and patients with drug-induced liver disease and with cryptogenic FHF have the poorest survival rates. ${ }^{18-20}$ Patients with Wilson's disease or malignancy-induced FHF rarely survive.

Dynamic variables useful in predicting the outcome of FHF include degree of hepatic encephalopathy, prothrombin time, factor $\mathrm{V}$ level, serum bilirubin, serum creatinine, alpha-fetoprotein level, arterial $\mathrm{pH}$, and arterial ketone body ratio. ${ }^{22}$ The degree of encephalopathy is a strong predictor of outcome. Among patients who reach only stage II encephalopathy, the possibility of spontaneous recovery is between $65 \%$ and $70 \%$, with

TABLE 5. 1-Year Survival Rate After OLTx

\begin{tabular}{lcc}
\hline \multicolumn{1}{c}{ Group } & $\begin{array}{c}\text { Patient } \\
\text { Survival }\end{array}$ & $\begin{array}{c}\text { Graft } \\
\text { Survival }\end{array}$ \\
\hline All FHF cases & $63 \%$ & $53 \%$ \\
All non-FHF cases & $78 \%$ & $70 \%$ \\
\hline
\end{tabular}


stage III between $40 \%$ and $50 \%$, and with stage IV $20 \%$ or lower. ${ }^{17}$

In recent years, sophisticated multivariate analysis and prognostic modelling have been applied to static and dynamic variables to assess the relative importance and interaction in predicting outcome. Bernuau et $\mathrm{al}^{19}$ from the Hôpital Beaujon, Clinchy, France, analyzed features from 115 consecutive patients with FHF caused by hepatitis B. Variables found to correlate best with survival were the factor $\mathrm{V}$ level $(P<.001)$, patient age $(P=.001)$, absence of HBsAg $(P=.06)$, and level of alpha-fetoprotein $(P=.07)$. Subsequently, Williams et al from the King's College Liver Unit (London) analyzed data on 588 patients admitted with FHF to their care, 310 of whom had acetaminophen toxicity. ${ }^{20,21}$ For the total cohort, the static variables found to be most important in predicting prognosis were patient age $(P$ $<.01)$, disease etiology $(P<.001)$, encephalopathy grade $(P<.05)$, and, for nonacetaminophen cases, duration of jaundice $(P<.001)$. Analysis of dynamic variables showed that admission and peak serum bilirubin and prothrombin times were important. In patients with acetaminophen-induced $\mathrm{FHF}$, arterial $\mathrm{pH}$ on admission and serum creatinine were also important.

Based on their multivariate analysis, the King's College group have proposed the following criteria for transplantation in patients with $\mathrm{FHF}{ }^{20,21}$ For acetaminophen hepatotoxicity: Arterial $\mathrm{pH}<7.30$ or the following three factors: prothrombin time $>100 \mathrm{sec}-$ onds, creatinine $>3.5 \mathrm{mg} \%$, and grade III or IV encephalopathy. For other causes of FHF: Prothrombin time $>100$ seconds or any three of the following: prothrombin time $>50$ seconds, bilirubin $>17.5 \mathrm{mg} \%(100 \mu \mathrm{mol})$, age younger than 10 years or older than 40 years, cryptogenic or drug-induced $\mathrm{FHF}$, or jaundice for more than 7 days before onset of encephalopathy.

Using both static and dynamic variables, important information of prognosis can be gained to estimate the probability of spontaneous recovery. These carefully defined criteria for judging prognosis are extremely valuable but need to be continuously re-evaluated and revised based on other advances in the management of FHF.

\section{COMPLICATIONS OF FHF}

The medical complications of FHF were discussed by Andres Blei, MD (Department of Medicine, Lakeside VA Medical Center and Northwestern Medical Center, Chicago, IL), and new approaches to their management were discussed by Gregory Gores, MD (Division of Gastroenterology, Mayo Clinic, Rochester, MN). Common complications of FHF include infections, hemodynamic changes, mental status changes, and brain edema.

Infections. Infections are a common complication and significant cause of death in patients with FHF. In a prospective study of 50 patients with $\mathrm{FHF}$ who had daily bacterial cultures, investigators at the FHF unit at King's College found evidence of infection in $90 \%$ of patients. ${ }^{23} \mathrm{~A}$ third of patients had fungal infections in addition to bacterial infections. Most patients had few systemic manifestations of infections such as fever or elevated white blood cell counts. Thus, without careful monitoring and routine cultures, many infections can be missed before death.

Spontaneous bacterial peritonitis also is common among patients with $\mathrm{FHF}$. Chu et $\mathrm{al}^{24}$ found that $32 \%$ of 82 patients with severe acute hepatitis and subacute hepatic necrosis developed bacterial peritonitis. Patients with peritonitis or other infections were more likely to develop renal failure and gastrointestinal bleeding and had a significantly higher mortality than did noninfected patients.

The frequency of severe infections during the course of FHF has led to trials of preventive therapy. Prophylactic therapies have focused on control of bowel flora, the suspected source of most bacteremias in FHF. In a controlled trial from the King's College FHF group, prophylactic antibiotics led to a significant decrease in bacterial infections. Although survival was greater in patients given prophylactic antibiotics, this did not reach statistical significance. ${ }^{25}$ However, the rate of successful transplantation was greater in patients given antibiotics, and the investigators concluded that prophylaxis was appropriate for all patients with FHF and stage III encephalopathy. In a separate study from Barcelona, Spain, investigators found that broad-spectrum antibiotics led to a decrease in mortality rate and shortened hospital time in patients with FHF. ${ }^{26}$ Thus, two recent controlled trials indicate that prophylactic antibiotics are appropriate in the management of FHF.

Hemodynamic Changes. Patients with FHF can experience marked changes in systemic and portal hemodynamics, including acute portal hypertension, systemic hyperdynamic circulation, and profound peripheral vasodilation. For instance, in one study, portal hypertension was present in 24 of 25 patients with FHF who underwent hepatic venous pressure measurements. ${ }^{27}$ Raised portal pressures correlated with the degree of architectural disruption of the liver and were most evident in patients with ascites and renal failure. Patients with FHF typically had a hyperdynamic circulation with a low systemic vascular resistance and markedly increased cardiac output similar to what is found in chronic liver disease. The cause of these circulatory changes are unclear; from studies of chronic liver disease, a variety of mediators have been proposed, including bile salts, prostaglandins, glucagon, endotoxin, serotonin, nitric oxide, and nonhumoral neural substances. The circulatory changes, which can be profound, are associated with renal vasoconstriction, a decrease in cerebral perfusion pressure (CPP), and hepatopulmonary syndrome. The renal vasoconstriction leads to a picture of renal failure similar to the hepatorenal syndrome observed in chronic liver disease. In addition, prolonged inappropriate arteriolar vasodilatation can interfere with the normal autoregulation of capillary oxygen consumption and predispose the patient to lactic acidosis.

In one clinical trial, ${ }^{28}$ prophylactic acetylcysteine or placebo was administered to 50 patients with acet- 
aminophen-induced FHF in an attempt to decrease tissue injury by augmenting intracellular sources of cysteine and glutathione. Therapy was associated with an increase in oxygen delivery and a decrease in lactic acidosis although cardiac output was increased and peripheral vascular resistance was further decreased. ${ }^{29}$

Brain Edema. In addition to encephalopathy, FHF is commonly associated with brain edema, which can evolve to an increase in intracerebral pressures (ICP), a common immediate cause of death in FHF. Increased ICP is uncommon in patients with stage I and II encephalopathy but eventuates in the majority of patients in stage IV coma. It is clear that there is an increase in brain water before brain edema becomes clinically apparent as increased ICP.

The cause of brain edema in FHF is not well defined; but it is probably multifactorial. Theoretically, it could be caused either by disruption of the blood-brain barrier with direct leakage of plasma into the cerebrospinal fluid (CSF) (vasogenic mechanism) or by cellular alterations that allow increased uptake of water into brain cells (cytotoxic mechanism). The majority of experimental evidence favors the latter mechanism, a concept that is supported by clinical observations that mannitol is effective and corticosteroids are ineffective in reducing ICP in FHF. Three hypotheses have been proposed to explain the cellular defect that leads to brain edema in FHF: (1) inhibition of $\mathrm{Na}^{+}-\mathrm{K}^{+}$adenosine triphosphatase (ATPase) activity; (2) astrocyte swelling; and (3) osmotic effects of accumulation of an intracellular molecule, possibly glutamine..$^{30,31}$

Further studies on the cause and prevention of complications of acute liver injury are needed. Three major areas deserve particular emphasis: (1) prevention of infections; (2) analysis of the prognostic implications of hemodynamic changes, renal failure, and metabolic acidosis; and ( 3 ) understanding the pathogenesis of brain edema. Optimal management of these complications of FHF may well lead to improvements in survival.

\section{INTRACEREBRAL PRESSURE MONITORING IN FHF}

The major cause of death in patients with FHF awaiting liver transplantation is brain edema. Furthermore, brain edema is found on autopsy in $80 \%$ of patients dying of FHF. Dr John Lake (Department of Medicine, University of California, San Francisco, CA) summarized recent findings using ICP monitoring, which has been increasingly used in patients with FHF to allow for proper management of brain edema and to aid in the decision to perform OLTx.

ICP monitoring had its foundation in the management of Reye's syndrome in the $1960 \mathrm{~s}$ and $1970 \mathrm{~s}^{32}$ These studies indicated that if cerebral perfusion pressure $(C P P=$ mean arterial pressure - ICP) remained $<40 \mathrm{~mm} \mathrm{Hg}$, death or severe neurological complications were all but certain. Concerns over complications of inserting ICP monitors led to attempts to develop clinical findings indicative of a low CPP. Sluggish pu- pillary reflexes, hyperventilation, and increased systemic blood pressure occur early with increasing ICP. Myoclonus, increased muscle tone, decorticate posturing, and seizures occur late. In studies of ICP at King's College, clinical manifestations commonly occurred with ICP of greater than $30 \mathrm{~mm} \mathrm{Hg}$, but there was a poor correlation between the height of the ICP and specific clinical signs..$^{33,34}$ Computed tomography (CT) scan of the brain has likewise been found to be unreliable in detecting early brain edema. Furthermore, transport of the patient to the radiology department for $\mathrm{CT}$ scan can precipitate increases in ICP and neurological damage.

Slightly more than half of transplantation programs in the United States routinely use ICP monitoring in management of cases of FHF. Three types of monitors have been used: epidural, subdural, and parenchymal. The epidural monitor is outside the dura and, therefore, is less invasive and has fewer complications. However, it is also somewhat less reliable than the subdural or parenchymal monitors. ICP monitoring has complications. A recent review of ICP monitoring ${ }^{35}$ indicated that the complication rates were $4 \%$ (6 of 160 ) for epidural, $20 \%$ (16 of 79) for subdural, and $22 \%$ (5 of 23 ) for parenchymal monitors. Deaths from infection or bleeding were reported with all three types of monitoring but were less common with the epidural $(\sim 1 \%)$ than with others (4\% to $5 \%$ ).

In many transplantation centers, epidural monitoring has become a standard practice for patients with FHF ${ }^{36}$ The monitor is placed at the onset of stage IV coma or if there is rapid progression into stage III coma. A brain CT scan is performed before placement, and any coagulopathy is corrected with fresh frozen plasma (to keep prothrombin time $<5$ seconds prolonged). The epidural ICP monitor is checked daily by neurosurgical consultants. A repeat $\mathrm{CT}$ scan is performed at removal of the ICP monitor.

ICP monitoring is valuable in guiding treatment, the goals of which are to maintain an ICP of $<20 \mathrm{~mm} \mathrm{Hg}$ and a CPP of $>50 \mathrm{~mm} \mathrm{Hg}$. A standardized approach to therapy has been adopted by the collaborating centers of the NIDDK Liver Transplantation Database. ${ }^{16,37}$ If the ICP rises above $20 \mathrm{~mm} \mathrm{Hg}$, (1) patients are hyperventilated to keep the $\mathrm{PCO}_{2}$ less than $25 \mathrm{~mm} \mathrm{Hg}$. If there is no response or a relapse, (2) mannitol is administered $(0.5$ to $1 \mathrm{~g} / \mathrm{kg})$ as a bolus intravenously and then as needed to keep serum osmolarity between 310 and $320 \mathrm{mOsm}$. If there is no response or a relapse with mannitol, (3) pentobarbital coma is induced using a bolus of 3 to $5 \mathrm{mg} / \mathrm{kg}$ intravenously. Although the response rate to therapy was high, relapses were common (Table 6).

ICP monitoring not only allows for rapid and appropriate therapy of brain edema but also for avoidance of manipulations that worsen ICP, such as excessive physical stimulation, suctioning of the airway, or changes in body position. ICP monitoring also has been helpful during the transplantation procedure to determine which anesthetic agents affect ICP the least. 
TABLE 6. Outcome of ICP Monitoring in Patients With FHF

\begin{tabular}{lccccc}
\hline \multicolumn{1}{c}{ Treatment } & No. of Episodes & \% of Response & Initial Pressure (Mean) & Change Pressure (Mean) & $\%$ of Relapse \\
\hline Hyperventilation & 18 & $82 \%$ & $18 \mathrm{~mm}$ & $3.5 \mathrm{~mm}$ & $71 \%$ \\
Mannitol & 11 & $72 \%$ & $26 \mathrm{~mm}$ & $4.6 \mathrm{~mm}$ & $75 \%$ \\
Barbiturate coma & 15 & $73 \%$ & $26 \mathrm{~mm}$ & $4.6 \mathrm{~mm}$ \\
\hline
\end{tabular}

From these studies, narcotics and barbiturates have been preferred to inhalation gases for anesthesia induction, and $\beta$-blockers have been preferred to nitroprusside for blood pressure control.

The value of ICP monitoring in selecting patients for OLTx has recently been documented in studies at the University of Nebraska, Omaha, NE. ${ }^{38}$ When ICP monitoring was introduced, the results were not used to decide which patients should or should not undergo OLTx. During this early period, seven patients with a CPP $<40 \mathrm{~mm}$ for more than 2 hours received transplants; all seven suffered brain death. Conversely, all patients whose CPPs remained $>50 \mathrm{~mm}$ recovered without neurological sequelae. Subsequently, no patients with low CPP for more than 2 hours received transplants, and none of those who underwent transplantation developed severe neurological sequelae.

Thus, ICP monitoring can be accomplished safely, is more reliable than CT scans, electroencephalograms, or neurological examination, and has excellent sensitivity and specificity in predicting brain injury. Monitoring can guide therapy of brain edema, avoiding harmful manipulations as well as titrating therapeutic decisions. ICP monitoring provides reliable criteria for avoidance of OLTx in patients with irreversible brain damage and provides evidence of impending brain death.

\section{OLTx FOR FHF: UCSF EXPERIENCE}

The experience in managing patients with FHF using OLTx at the UCSF was reported by Dr Nancy Ascher (Department of Surgery, UCSF). Results using an organized medical-surgical-transplantation approach have been excellent. ${ }^{37}$ The approach focuses on prompt diagnosis, prospective monitoring of ICP, aggressive treatment of complications, and early listing for liver transplantation. If patients have prolonged periods of compromised intracranial perfusion, they are removed from the transplantation list.

Between 1988 and 1992, 60 patients with FHF were evaluated for possible OLTx for FHF. Among 24 who presented with stage II to III encephalopathy, 11 received transplants (2 others died, and 11 recovered spontaneously). Among 36 patients presenting in stage IV coma, 17 received transplants (16 others died, and 3 recovered without OLTx). Donor livers were obtained quickly, 15 within 1 day of listing and 13 more within 1 to 3 days. The 1-year patient survival rate was $92 \%$, and the graft survival rate was $83 \%$. The 3 deaths were caused by (1) aspiration pneumonia and cytomegalovirus infection at 5 months, (2) aspergillus brain abscess at $1 \frac{1}{2}$ months, and (3) progressive cerebral edema after primary nonfunction at 3 days after OLTx. Graft failures were frequent, perhaps because of the use of $\mathrm{ABO}$ incompatible livers. The $7 \mathrm{graft}$ failures leading to retransplantation were caused by vascular rejection $(2$ patients), acute rejection ( 2 patients), chronic rejection ( 1 patient), and acute hepatitis $B$ ( 2 patients). Neurological sequelae were mild and limited to only 2 patients. Other chronic complications included (1) a patient with fulminant cryptogenic hepatitis who developed chronic hepatitis B with compensated cirrhosis $2 \frac{1}{2}$ years after transplantation; (2) a patient with fulminant hepatitis A who developed chronic hepatitis $\mathrm{C}$ but who has normal liver function tests 2 years after transplantation; and (3) 2 patients with fulminant hepatitis $B$ who have developed cirrhosis with normal enzymes at 3 years after transplantation.

Survival results in patients with FHF who underwent transplantation at UCSF have been comparable with those of patients with nonfulminant diseases. These data show that excellent results can be achieved with OLTx for FHF when strict criteria are used for selection and when patients' conditions are managed with an organized and aggressive approach.

\section{AUXILIARY LIVER TRANSPLANTATION}

OLTx for FHF requires that the damaged liver be removed and that the patient be committed to a lifetime of immunosuppression. The possibility of recovery from FHF makes attractive the option of auxiliary liver transplantation, in which the native liver is left in place. Dr Bruce Jarrell (Chairman of Surgery, University of Arizona Health Science Center, Tucson, AZ) provided an overview of auxiliary liver transplantation for FHF.

The advantages of auxiliary transplantation in FHF are the temporary requirement for immunosuppression drugs until the host liver recovers and the relative ease of surgery. Two types of auxiliary liver support are possible: heterotopic and orthotopic.

In auxiliary heterotopic transplantation, the liver graft is placed in the right upper quadrant beside the native liver. In orthotopic auxiliary transplantation, a portion of the native liver is removed and replaced with a reduced-size graft. Auxiliary heterotopic transplantation is technically easier than orthotopic transplantation but suffers from competition between the graft and native liver for portal blood supply, the tenuous nature of the blood supply to the graft, problems of venous congestion, and potential lack of space. In recent years, there have been seven reports of heterotopic trans- 
plants for FHF. Three patients died shortly after transplantation; four are living, and three have had recovery of the native liver and have stopped immunosuppression. Recovery of the native livers occurred at 5 months, 6 months, and 22 months, respectively. ${ }^{39,40}$

The major difficulties with auxiliary orthotopic transplantation relate to the technical difficulties involved in resection of the left lateral segment of the native liver and placement of the graft (frequently a reduced-size graft) at that site. ${ }^{41}$ This operation is particularly difficult in unstable patients with FHF and severe coagulopathy. However, the auxiliary orthotopic transplant has a more secure portal blood supply than the heterotopic transplant. Among seven patients from Hanover, Germany, and Nebraska that have been reported, three survived. ${ }^{42}$ Two deaths were caused by development of aplastic anemia in patients with fulminant cryptogenic hepatitis.

In summary, auxiliary liver transplantation has been used successfully in 7 of 12 patients $(60 \%)$ with FHF. Several technical problems with auxiliary transplantation need further evaluation. The advantages of not taking immunosuppressive drugs chronically may prove important once the overall survival of this technique has sufficiently improved.

\section{ARTIFICIAL HEPATIC SUPPORT SYSTEMS}

In recent years, there has been an increased interest in the use of hepatic support systems in patients with FHF to provide a bridge until the native liver recovers function spontaneously or until an appropriate donor liver is available. Breakthroughs in basic and applied research have provided innovative approaches to the possibility of artificial hepatic support. ${ }^{43,44}$ Use of a cellbased therapy for extracorporeal hepatic support was discussed by Dr Norman Sussman (Assistant Professor, Department of Medicine and Pathology, Baylor College of Medicine, Houston, TX).

Initial attempts at developing an artificial hepatic support were focused on various forms of dialysis or hemoperfusion using cartridges and membranes that would remove low-molecular weight toxins. ${ }^{43}$ Charcoal hemoperfusion enjoyed considerable attention in the late $1970 \mathrm{~s}$ and early $1980 \mathrm{~s}$, but subsequent careful evaluations failed to show evidence of benefit of the procedures, ${ }^{20,44}$ suggesting that something more than removal of toxins was required to prolong life in hepatic-failure patients. These considerations led to investigation of extracorporeal-assist devices that might provide both detoxifying and synthetic hepatic functions. The major focus of interest has been the use of cell-based extracorporeal devices.

Several types and sources of hepatocytes have been investigated for use in extracorporeal-assist devices. The ideal hepatocyte would be (1) human in origin, (2) of normal (nonmalignant) phenotype, (3) readily available, (4) rapidly and easily grown in cell culture to high density, (5) stable and remaining in a well-differentiated state for days or weeks, and (6) capable of the full range of synthetic and detoxifying features of mature hepatocytes. Of course, the ideal hepatocyte for these devices has not been identified. Normal human hepatocytes are not readily available, grow slowly in primary cell culture, rarely survive for more than a few weeks, and usually rapidly lose their differentiated state and metabolic functions. Alternatives to primary human hepatocytes have been primary hepatocytes from other mammalian species (pig, rat, and dog) and immortalized human liver cell lines.

Sussman et $\mathrm{al}^{45}$ have investigated a human hepatoblastoma cell line (C3A cells) that shows many characteristics of differentiated mature hepatocytes, including contact inhibition, detoxification of ammonia to urea and glutamine, metabolism of amino acids, gluconeogenesis, and integrity of the $\mathrm{P} 450$ system. They have reported the development of a hepatocyte-assist device using C3A cells grown in the extracapillary space of a hollow-fiber dialyzer. The device has the metabolic capacity of approximately $200 \mathrm{~g}$ of normal liver. In preliminary studies in a dog model of FHF with $100 \%$ mortality, the assist device led to recovery of consciousness, decreases in alanine aminotransferase(ALT) levels, and survival in four of five animals.

Preliminary attempts to use the C3A-based hepatocyte-assist device in humans with severe liver failure also were reported. ${ }^{46}$ The system used is similar to hemodialysis: venous blood is pumped through hollow fibers and returned to the patient at a flow rate of approximately $150 \mathrm{~mL} / \mathrm{min}$. A second flow path is maintained by the continuous ultrafiltration of plasma into the extracapillary space at a rate of $20 \mathrm{~mL} / \mathrm{min}$. The metabolic effects of the cartridge appear to be independent of ultrafiltration; delivering the ultrafiltrate back to the blood stream allows efficient delivery of high-molecular weight products such as clotting factors.

To date, six patients have been treated with the hepatic-assist device. Improvements in serum ALT levels, prothrombin time, galactose-elimination capacity, and clinical status were noted in five patients during use for 1 to 6 days on a continuous basis. Only one patient survived, a 12-year-old girl with syncytial giant-cell hepatitis who recovered without OLTx after 58 hours on the assist device and who is alive and well 1 year later. A second patient appeared to recover from $\mathrm{FHF}$ but succumbed to sepsis several days later. The remaining patients died without OLTx.

Other hepatic-assist devices are being evaluated. Demetriou et $\mathrm{al}^{47}$ have recently reported successful treatment of FHF in dogs with a hepatic-assist device using primary pig hepatocytes. This experience is now being applied to humans with FHF ${ }^{48}$ Thus, new refinements in cell-based hepatic-assist devices have provided new hope for this approach to medical therapy of FHF.

\section{HEPATOCYTE TRANSPLANTATION}

Achilles A. Demetriou, MD, PhD (Director of Liver Support Unit, Cedars Sinai Medical Center, Los Angeles, CA), discussed the use of hepatocyte transplantation for management of FHF. This innovative 
alternative approach uses transplantation of hepatocytes rather than of the whole organ. This approach would have the advantages of avoiding both major surgery and the use of a whole liver; it is technically simple and allows the use of one or more living-related donors and multiple courses of treatment. This technique also might provide temporary hepatic support without committing the patient to lifelong immunosuppression. Hepatocyte transplantation has not been used in humans with liver disease but has been applied with partial success in several animal models of liver diseases.

The feasibility of hepatocyte transplantation has been documented in studies of genetically deficient animals. Transplantation of normal rat hepatocytes by intraportal infusion into analbuminic rats was followed by increasing levels of serum albumin 14 to 28 days later, which persisted for several months. ${ }^{49}$ Similarly, in jaundiced Gunn rats with genetic deficiency of glucuronyl transferase (an animal model of CrigglerNajjar syndrome), transplantation of hepatocytes from normal rats resulted in decreases in serum bilirubin levels and appearance of conjugated bilirubin in the bile. ${ }^{50}$ These studies have documented the long-term viability of transplanted hepatocytes and identified problems in optimizing the technique. For example, the number and percentage of cells surviving can be increased by using hepatocytes attached to beads coated with a collagen matrix ${ }^{51}$ However, these cells remain immunogenic, and if allogeneic hepatocytes are used, a lasting problem will be the need for immunosuppression. Rejection can be partially circumvented by microencapsulation of hepatocytes ${ }^{52}$; unfortunately, the microcapsules usually induce an intense inflammatory reaction that results in poor hepatocyte function. The site of infusion of hepatocytes also is important in achieving efficient function. Intraportal, intrasplenic, and intraperitoneal infusions all have relative strengths and shortcomings. For instance, infusion of large numbers of hepatocytes into the portal vein can induce portal hypertension.

Hepatocyte transplantation for transfer of genes to individuals with genetic diseases has advanced from animal experimentation to pilot trials in humans. This approach was developed in the hypercholesterolemic Watanabe rabbit, which has a genetic defect in the lowdensity lipoprotein (LDL) receptor similar to that of humans with familial hypercholesterolemia. ${ }^{53}$ Hepatocytes were obtained from the animals by partial hepatic resection, grown in cell culture, and then transfected with the normal rabbit LDL receptor gene using a retrovirus vector. After reinfusion into the portal vein, the viability of the hepatocytes was shown functionally by decrease in serum cholesterol and histologically by identification of transfected hepatocytes expressing normal LDL receptor messenger RNA (mRNA). Approximately $2 \%$ of normal functional hepatocyte mass was provided by the transplanted hepatocytes, and these cells continued to function for several months. These innovative studies have led to pilot trials of au- tologous hepatocyte transplantation in humans with homologous type II hypercholesterolemia. ${ }^{54}$

There have been few studies on hepatocyte transplantation for FHF. Using an animal model of liver insufficiency, Demetriou et al have evaluated the ability of transplanted hepatocytes to provide liver support. ${ }^{55}$ Rats underwent $90 \%$ hepatectomy, which led to death in $24 \pm 8$ hours after surgery in controls. Animals treated with infusions of either allogeneic or syngeneic hepatocytes before hepatectomy survived for $28 \pm 8$ hours. Infusions of hepatocytes at the time of hepatectomy also did not prolong survival. One limitation in using hepatocyte transplantation for treating FHF is the need for a period of 1 to 3 days for cell engraftment before function. In addition, the altered milieu of FHF may not provide a suitable environment for transplanted hepatocytes: the same toxin that harmed the native liver may harm the infused liver cells, and the usual hepatic architecture and balance of growth factors, cytokines, and nutrients necessary for hepatocyte growth and regeneration may be lacking in FHF. Thus, hepatocyte transplantation is a promising approach to hepatic support in FHF but has yet to be developed sufficiently to attempt its use in patients. Because of limitations in the numbers of hepatocytes that can be transplanted successfully, this technique may be more applicable to other situations, such as correction of inherited metabolic defects.

\section{PROSTAGLANDIN THERAPY FOR FHF}

Specific therapies for FHF are not currently available. Antiviral therapies have shown little evidence of benefit. ${ }^{56-58}$ On the other hand, therapies directed at limiting cell damage, providing cytoprotection, and stimulating regeneration might have a role in management of FHF. Among cytoprotective agents, the prostaglandins have been most actively investigated.

Dr Gary A. Levy (Director, Division of Gastroenterology, Department of Medicine, Toronto General Hospital, Toronto, Ontario, Canada) provided an overview on prostaglandins and their potential role as therapy of FHF. The prostaglandins are a group of polyunsaturated fatty acids with major, diverse metabolic actions on cells. ${ }^{59}$ Prostaglandins are made in all cells, the liver being particularly rich in the prostaglandin $\mathrm{E}(\mathrm{PGE})$ series. When administered systemically, PGE has multiple effects on smooth muscle tissue, inducing widespread vasodilation, increased blood flow, hypotension, increased cardiac output, bronchodilation, intestinal hypermotility, and uterine contractions. Exogenously administered prostaglandins can protect the liver against several forms of cell injury, including hypoxic, drug-induced, viral, and immune injury. ${ }^{60,61}$ The availability of $\mathrm{PGE}_{1}$ and $\mathrm{PGE}_{2}$ for human use has provided an impetus to evaluate these agents in several liver diseases, including FHF.

Sinclair et $\mathrm{al}^{62}$ from Toronto, Canada, evaluated $\mathrm{PGE}_{1}$ in 17 patients with FHF in an open label-pilot study. $\mathrm{PGE}_{1}$ was administered by continuous intravenous infusion at a rate of up to $0.6 \mu \mathrm{g} / \mathrm{kg} / \mathrm{hr}$ for as 
long as 28 days. Infusions of $\mathrm{PGE}_{1}$ were generally well tolerated. Several patients had prompt improvements in aminotransferases. Most impressively, 12 patients survived without transplantation, a rate $(70 \%)$ far in excess of that in most series on FHF. Unfortunately, a subsequent uncontrolled study of FHF from France ${ }^{63}$ failed to confirm the benefit of prostaglandin therapy.

Based on their initial beneficial results, Levy et al $^{64}$ began a prospective, randomized, double-blind controlled study of $\mathrm{PGE}_{1}$ therapy in cases of viral- and drug-induced FHF. Forty-one patients with FHF were admitted to this trial; 20 received $\mathrm{PGE}_{1}$, and 21 received placebo by continuous intravenous infusions for up to 7 days. Overall survival was similar with both treatments: $40 \%$ of $\mathrm{PGE}_{1}$ and $38 \%$ of placebo recipients survived. Analysis of subgroups suggested that there might be some benefit of $\mathrm{PGE}_{1}$ therapy in patients with drug-induced FHF and viral hepatitis early in its course. However, diarrhea, fever, and mild hypotension occurred in patients receiving $\mathrm{PGE}_{1}$ therapy. In view of these findings, routine use of prostaglandins for FHF outside of controlled trials must be discouraged.

\section{EXTRACORPOREAL LIVER SUPPORT}

Dr Byers Shaw (Chairman, Liver Transplantation Program, University of Nebraska, Medical School, Omaha, NE) summarized recent experience using an extracorporeal liver (ECL) support system in the management of FHF. In this technique, the patient's circulation is connected to a liver outside of the body. The organ used for cross circulation may be human or from another species. The procedure was introduced by Otto in the late 1950 s and then used sporadically. During the $1970 \mathrm{~s}, 40$ patients with more than 90 episodes of FHF were treated; 3 donors were human, 67 were primates, 23 were pigs, and 2 were calves; acute survival was $35 \% .^{65}$

The University of Nebraska has recently applied this technique using unwanted human donor livers in three patients with FHF ${ }^{65}$ The patients were a 16 -year-old and a 38-year-old with FHF of unknown cause and a 6-year-old with Stevens Johnson syndrome. The first patient underwent ECL support for 3 days with rapid improvements in serum bilirubin and ammonia levels and decreases in ICP. The second patient underwent treatment for 24 hours using a liver with marked fatty infiltration; there was minimal improvement in bilirubin and ammonia levels. The first two patients subsequently underwent transplantation successfully. The third patient underwent perfusion for $3 \frac{1}{2}$ days with decrease in bilirubin and ammonia but progressive failure of other organ systems and death.

Five cases of ECL support using livers of other species have been reported recently from other institutions. At Johns Hopkins University Medical Center, a porcine liver was used for 4 hours in a 20 -year-old patient with FHF caused by hepatitis B: consciousness improved, and the patient underwent successful OLTx 8 hours later. ${ }^{66}$ Four patients were treated with ECL support using porcine liver at Duke University Medical
TABLE 7. Median Survival Time After Hamster-to-Rat Xenotransplantation

\begin{tabular}{lcc}
\hline \multicolumn{1}{c}{$\begin{array}{c}\text { Immunosuppressive } \\
\text { Regimen }\end{array}$} & $\begin{array}{c}\text { Heart Survival } \\
(\mathbf{d})\end{array}$ & $\begin{array}{c}\text { Liver Survival } \\
(\mathbf{d})\end{array}$ \\
\hline None & 3 & 7 \\
FK506 alone & 4 & 35 \\
FK506 + cyclophosphamide & $>90$ & $>90$ \\
FK506 + brequinar & $>90$ & $>90$ \\
\hline
\end{tabular}

Center; transient improvements in neurological status, ICP, and hepatic function occurred in all four patients. One patient received an OLTx after four perfusions and is well; the other three died of sepsis, cerebral edema, and multisystem failure, respectively. ${ }^{67}$

Thus, the conditions of four of eight patients in the modern era have been managed successfully with ECL support, bridging the period of FHF until OLTx could be performed. Deaths that occurred in three patients were unrelated to the ECL technique. Thus, ECL support offers an attractive means of temporary support for patients with severe FHF. Improvements in handling ECL, monitoring its efficacy, and handling problems of species incompatibility are needed before this technique can be more broadly applied.

\section{XENOTRANSPLANTATION}

Dr John Fung (Chief, Division of Transplantation Surgery, University of Pittsburgh, Pittsburgh, PA) provided an update and overview on xenotransplantation and its potential role in management of FHF. The concept of using a xenograft for transplantation is not new. Before 1992, 33 human xenotransplantations were reported, most before the availability of cyclosporin A and FK506. The longest survival was 9 months, reported in a patient given a chimpanzee kidney. ${ }^{68}$ The most successful previous experience with baboon xenotransplantation was in a neonate with hypoplastic left-heart syndrome who received a baboon heart and survived 20 days, dying eventually of humoral-mediated rejection. ${ }^{69}$ Thus, xenotransplantation was unsuccessful largely because of problems with humoral and cell-mediated rejection.

The development of FK506 has allowed for a reassessment of xenotransplantation. In animal studies, FK506 by itself does not prolong survival of hamster heart xenografts in rats; however, the combination of FK506 with antiproliferative drugs, such as with RS61443, brequinar, or cyclophosphamide, does. ${ }^{70}$ In liver xenografts, combinations of FK506 with antiproliferative agents led to indefinite survival of grafts (Table 7 ). The antiproliferative agents seem to act by blocking formation of cytotoxic antibodies and eventually can be discontinued, whereas FK506 blocks development of cellular rejection, and continuous therapy is needed.

These experiments prepared the way for attempts at xenotransplantation in humans. The general protocol of therapy used depletion of any natural antibody 
using plasmapheresis and affinity absorption, disruption of the inflammatory cascade with corticosteroids, blockage of antibody production by cyclophosphamide and/or brequinar, and inhibition of cellular rejection with FK506 and corticosteroids.

Recently two types of xenograft donors have been evaluated: pigs and baboons. Porcine xenotransplantation was used by investigators from Cedars Sinai Hospital in Los Angeles in an attempt to support a critically ill patient with FHF until an appropriate human donor liver was available. ${ }^{71}$ After plasmapheresis against a porcine kidney to reduce antiporcine antibodies, the patient underwent xenotransplantation under therapy with cyclosporin A, azathioprine, cyclophosphamide, and corticosteroids. Initial hepatic xenograft function was good, but after 25 hours the graft began to fail, ICP rose, and she died a few hours later. Autopsy showed widespread hepatic necrosis with plugging and thrombosis of arterioles and presence of immunoglobulin $G$ (IgG) on endothelial cells throughout the liver. Similar pathology was noted in porcine livers used in crosscirculation studies in patients with FHF. ${ }^{72}$ Thus, problems of immediate rejection and incompatibility limit the usefulness of porcine livers in xenotransplantation as well as extracorporeal liver support for FHF.

In 1992, two patients with end-stage chronic hepatitis $B$ received orthotopic baboon liver xenografts at the University of Pittsburgh Medical Center. ${ }^{73}$ The rationale for xenotransplantation in these patients was that the baboon is not susceptible to hepatitis B and therefore reinfection could be avoided. ${ }^{74}$ The patients and baboons were carefully matched for blood type and absence of pre-existing IgG xenoantibodies. Immunosuppressive therapy included FK506, cyclophosphamide, and corticosteroids. Initial graft function was good. The baboon livers were small in comparison with those of humans ( 450 to $550 \mathrm{~g}$ vs. 1,200 to $1,500 \mathrm{~g}$ ) but grew rapidly to a size appropriate to the recipient. In both cases, baboon proteins (albumin, transferrin, C3) were detected in serum, but functions seemed normal (coagulation and complement cascade). Unfortunately, both patients developed persistent, poorly explained jaundice, multiple infections, and multisystem failure. Patient no. 1 died after 74 days with invasive aspergillosis; patient no. 2 died after 26 days with septicemia.

Thus, the results of xenotransplantation to date are promising but far from satisfactory. Baboon liver xenotransplantation for FHF has not been reported but may also be appropriate in view of the increasing problem of human donor liver availability and the possibility of using the baboon liver to sustain the critically ill patient with FHF until an appropriate human liver is available. The problems that blocked success in the past, immediate vascular rejection and severe cellular rejection, seem to be manageable with appropriate immunosuppression, at least with baboon livers. What remains are problems of a technical and metabolic nature. Furthermore, the shortage of baboons, ethical considerations in using primates, and issues of trans- mission of infections remain as very significant issues. $^{75}$

\section{SUMMARY AND RECOMMENDATIONS}

OLTx should be considered standard management for patients with FHF who are in stage III to IV hepatic encephalopathy and who fulfill criteria that indicate that survival with medical therapy alone is unlikely and that irreversible neurological damage has not occurred. Long-term survival in such patients with FHF is similar to that of patients with chronic end-stage liver disease, if adverse donor (ABO incompatibility) and recipient factors (need for ventilatory support) are controlled for in the analysis. Strict criteria for patient selection and timing of OLTx are of great importance in the outcome of transplantation: the decision to perform OLTx in FHF should be based on careful assessment of both static and dynamic factors. Static factors of importance are cause of FHF and patient age. Dynamic factors of importance are stage of encephalopathy, prothrombin time (or factor $V$ levels), serum bilirubin, creatinine, arterial $\mathrm{pH}$, and alpha-fetoprotein levels. Medical models for predicting survival are of great help in reaching a decision for OLTx. Exclusion criteria are also important: overwhelming infections and sustained impairment in cerebral perfusion are contraindications for OLT, which makes careful monitoring for infections and intracerebral pressure essential. At the present time, use of innovative approaches to managing FHF, such as auxiliary transplants, living related donors, xenografts, extracorporeal human liver, and artificial hepatic support devices, are extremely promising but must be considered experimental.

Several recommendations can be made to improve the general management of patients with FHF. In medical practice, important goals are (1) encouragement of early referral of patients with FHF to transplantation centers, and (2) increased use of HAV and HBV vaccine. In public policy, important steps are (1) creation of a new UNOS category for patients with acute FHF, (2) increased public programs to promote awareness about organ donation, (3) change in reimbursement practices for OLTx for patients with FHF by Medicare and Medicaid, and (4) more aggressive labeling guidelines for hepatotoxic drugs. In clinical research, important areas are (1) prospective studies on the epidemiology of FHF, (2) development of clear diagnostic criteria and better coding systems for this diagnosis, and (3) careful design and performance of clinical trials of new and innovative approaches to management and treatment of FHF. In basic research, important studies are (1) in vitro and in vivo analyses of the causes of brain edema in FHF, (2) analyses of the role of cytokines and hepatotrophic growth factors in liver cell injury and FHF, (3) basic virological and cell biological investigations into the etiology of cryptogenic FHF (non-A, non-B, and non-C hepatitis), and (4) development of animal models of severe hepatic injury to aid in the study of pathogenesis as well as therapy and management of FHF. 
Acknowledgment: The Digestive Diseases Advisory Board was established by Congress in 1980 and chartered to provide oversight and advice to the Federal Government of important issues that will help to reduce the impact of digestive diseases. The current members of the Digestive Diseases Advisory Board are as follows: Phillip P. Toskes, MD (Chairman), Jerome D. Waye, MD (Vice Chairman), Gordon D. Benson, MD, E. Rolland Dickson, MD, Janet D. Elashoff, $\mathrm{PhD}$, Norma J. Goodwin, MD, Charles H. Halsted, MD, Elaine I. Hartsook, PhD, RD, Lennox J. Jeffers, MD, Katherine F. Jeter, EdD, William J. Klish, MD, Robert A. Levine, MD, Sidney J. Malawer, MD, Thomas E. Starzl, MD, PhD, Richard L. Sterkel, MD, Thelma K. Thiel, Joanne A.P. Wilson, MD, R. Yvonne Young, MSW, LICSW, and Tommie Sue Tralka (Executive Director).

\section{REFERENCES}

1. Jones EA, Schafer DF. Fulminant hepatic failure. In: Zakim D, Boyer TD, eds. Hepatology. A textbook of liver disease. Ed 2. Philadelphia: Saunders, 1990:460-492.

2. Wright TL. Etiology of fulminant hepatic failure: is another virus involved? Gastroenterology 1993; 104:648-653.

3. Feray C, Gigou M, Samuel D, Reyes G, Bernuau J, Reynes M, Bismuth $\mathrm{H}$, et al. Hepatitis $\mathrm{C}$ virus RNA and hepatitis $B$ virus DNA in serum and liver of patients with fulminant hepatitis. Gastroenterology 1993;104:549-555.

4. Phillips MJ, Blendis LM, Poucell S, Patterson J, Petric M, Roberts E, Levy GA, et al. Syncytial giant-cell hepatitis. Sporadic hepatitis with distinctive pathological features, a severe clinical course, and paramyxoviral features. N Engl J Med 1991;324:455460.

5. Omata M, Ehata T, Yokosuka O, Hosoda K, Ohto M. Mutations in the precore region of hepatitis $B$ virus DNA in patients with fulminant and severe hepatitis. N Engl J Med 1991;324:16991704 .

6. Liang TJ, Hasegawa K, Rimon N, Wands JR, Ben-Porath E. A hepatitis $B$ virus mutant associated with an epidemic of fulminant hepatitis. N Engl J Med 1991;324:1705-1709.

7. Carman WF, Fagan EA, Hadziyannis S, Karayiannis P, Tassopoulos NC, Williams R, Thomas HC. Association of a precore genomic variant of hepatitis $B$ virus with fulminant hepatitis. HePatology $1991 ; 14: 219-222$.

8. Lugassy C, Bernuau J, Thiers V, Krosgaard K, Degott C, Wantzin P, Schalm SW, et al. Sequences of hepatitis B virus DNA in the serum and liver of patients with acute benign and fulminant hepatitis. J Infect Dis 1987; 155:64-71.

9. Wright TL, Marnish D, Combs CV, Kunn M, Donegan E, Ferrell $\mathrm{L}$, Lake $\mathrm{J}$, et al. Hepatitis $\mathrm{B}$ virus and apparent non-A, non-B hepatitis. Lancet 1992;339:952-955.

10. Centers for Disease Control. Summary of notifiable diseases, United States, 1991. MMWR 1992;40:53.

11. Alter MJ, Hadler SC, Margolis HS, Alexander J, Hu P-Y, Judson FH, Mares A, et al. The changing epidemiology of hepatitis B in the United States: need for alternative vaccination strategies. JAMA 1990;263:1218-1222.

12. Alter MJ, Margolis HS, Krawczynski K, Judson FN, Mares A, Alexander WJ, Hu PY, et al. The natural history of communityacquired hepatitis $C$ in the United States. N Engl J Med 1992;327:1899-1905.

13. National Center for Health Statistics. Multiple cause of death data. Public use data tapes, 1980-1988. Springfield, VA: National Technical Information Services, 1988.

14. National Center for Health Statistics. National hospital discharge survey. Public use data tapes, 1988-1990. Springfield, VA: National Technical Information Services, 1990.

15. Belle SH, Beringer KC, Murphy JB, Plummer CC, Breen TJ, Edwards EB, Daily OP, et al. Liver transplantation in the United
States: 1988 to 1990 . In: Terasaki P, ed. Clinical transplants 1991. Los Angeles: UCLA Tissue Typing Laboratory, 1991:1329.

16. Detre KM. The NIDDK Liver Transplantation Database. In: Terasaki P, ed. Clinical transplants 1986. Los Angeles: UCLA Tissue Typing Laboratory, 1986:29-33.

17. Trey $C$. The fulminant hepatic failure surveillance study: brief review of the effects of presumed etiology and age on survival. CMAJ 1972; 106:525-526.

18. Karvountzis GG, Redeker AG. Relation of alpha-fetoprotein in acute hepatitis to severity and prognosis. Ann Intern Med 1974;80:156-160.

19. Bernuau J, Goudeau A, Poynard T, Dubois F, Lesage G, Yvonnet B, Degott C, et al. Multivariate analysis of prognostic factors in fulminant hepatitis B. HEPATOLOGY 1986;6:648-651.

20. O'Grady JG, Gimson AES, O'Brien CJ, Pucknell A, Hughes RD Williams $R$. Controlled trials of charcoal hemoperfusion and prognostic factors in fulminant hepatic failure. Gastroenterology 1988;94:1192-1198.

21. O'Grady JG, Alexander GJM, Hayllar KM, Williams R. Early indicators of prognosis in fulminant hepatic failure. Gastroenterology 1989;97:439-445.

22. Scaiola A, MacMathuna P, Langley PG, Gove CD, Hughes RD, Williams R. Determination of the ketone body ratio in fulminant hepatic failure. Hepatogastroenterology 1990;37:413-416.

23. Rolando N, Harvey F, Brahm J, Philpott-Howard J, Alexander G, Gimson A, Casewell M, et al. Prospective study of bacterial infection in acute liver failure: an analysis of 50 patients. HePATOLOGY 1990;11:49-53.

24. Chu C-M, Chiu K-W, Liaw Y-F. The prevalence and prognostic significance of spontaneous bacterial peritonitis in severe acute hepatitis with ascites. HEPATOLOGY 1992; 15:799-803.

25. Rolando N, Gimson A, Wack J, Phillop-Howard J, Casewell M, Williams R. Prospective controlled trial of selective and enteral antimicrobial regimen in fulminant liver failure. HEPATOLOGY $1993 ; 17: 196-201$.

26. Salmeron JN, Tito L, Rimola A, Mas A, Navasa MA, Llach J, Gines A, et al. Selective intestinal decontamination in the prevention of bacterial infection in patients with acute liver failure. J Hepatol 1992; 14:208-285.

27. Navasa M, Garcia-Pagan J-C, Bosch J, Riera JR, Bariares R, Mas A, Bruguera M, et al. Portal hypertension in acute liver failure. Gut 1992;33:965-968.

28. Keays R, Harrison PM, Wendon JA, Forbes A, Gove C, Alexander GJM, Williams R. Intravenous acetylcysteine in paracetamol induced fulminant hepatic failure: a prospective controlled trial. Br Med J 1991;303:1026-1029.

29. Harrison PM, Wendon JA, Gimson AES, Alexander GJM, Williams R. Improvement by acetylcysteine of hemodynamics and oxygen transport in fulminant hepatic failure. N Engl J Med $1991 ; 324: 1852-1857$.

30. Swain M, Butterworth RF, Blei AT. Ammonia and related amino acids in the pathogenesis of brain edema in acute ischemic liver failure in rats. HEPATOLOGY 1992; 15:449-453

31. Takahashi H, Koehler RC, Brasilow SW, Traystman RJ. Inhibition of brain glutamine accumulation prevents cerebral edema in hyperammonemic rats. Am J Physiol 1991;261:H825-H829.

32. Hanid MA, Davies M, Mellon PJ, Silk DBA, Strunin L, McCabe JJ, Williams R. Clinical monitoring of intracranial pressure in fulminant hepatic failure. Gut 1980;21:866-869.

33. Canalese J, Gimson AES, Davis C, Mellon PJ, Davis M, Williams R. Controlled trial of dexamethasone and mannitol for the cerebral oedema of fulminant hepatic failure. Gut 1982;23:625-629.

34. Brajtbord D, Parks RI, Ramsay MA, Paulsen AW, Valek TR Swygert TH, Klintmalm GB. Management of acute elevation of intracranial pressure during hepatic transplantation. Anesthesiology 1989; 70:139-141.

35. Blei AT, Olafsson S, Webster S, Levy R. Complications of intracranial pressure monitoring in fulminant hepatic failure. Lancet $1993 ; 341 ; 157-158$.

36. Lidofsky SD, Lake JR, Read AE, Wright TL, Prager MC, Ascher NL, Roberts BF, et al. Liver transplantation for fulminant he- 
patic failure: the role of intracranial pressure monitoring [Abstractl. Gastroenterology 1990;98:A604.

37. Ascher NL, Lake JR, Emond JC, Roberts JP. Liver transplantation for fulminant hepatic failure. Arch Surg 1993;128:677-682.

38. Inagaki M, Shaw B, Schafer D, Pillen T, Langnas A, Stratta R, Donovan J, et al. Advantages of intracranial pressure monitoring in patients with fulminant liver failure [Abstract]. Gastroenterology 1992;102:A826.

39. Moritz MJ, Jarrell BE, Munoz SJ, Maddrey WC. Regeneration of the native liver after heterotopic liver transplantation for fulminant hepatic failure. Transplantation 1993;55:952-954.

40. Moritz MJ, Jarrell BE, Armenti V, Radomski J, Carabasi RA, Zeitoun G, Columbus K, et al. Heterotopic liver transplantation for fulminant hepatic failure-a bridge to recovery. Transplantation 1990;50:524-526.

41. Gubenatis G, Pichlmayr R, Kemnitz J, Gratz K. Auxiliary partial orthotopic liver transplantation (APOLT) for fulminant hepatic failure: first successful case report. World J Surg 1991;15:660665 .

42. Shaw BH, Jr, Cattral M, Langas AN, Heffron TG, Fox IJ. Orthotopic auxiliary liver transplantation: the treatment of choice for acute liver failure? [Abstract]. HEPATOLOGY 1993; 18:66A

43. Takahashi T, Malchesky PS, Nose Y. Artificial liver: state of the art. Dig Dis Sci 1991;36:1327-1340.

44. Pappas SC. Fulminant hepatic failure and the need for artificial liver support. Mayo Clin Proc 1988;63:198-200.

45. Sussman NL, Chong MG, Koussayer T, He D-E, Shang TA, Whisennand $\mathrm{HH}$, Kelly JH. Reversal of fulminant hepatic failure using an extracorporeal liver assist device. HEPATOLOGY 1992;16:60-65.

46. Sussman NL, Finegold MJ, Kelly JH. Recovery from syncytial giant-cell (SGCH) hepatitis following treatment with an extracorporeal liver assist device (ELAD) [Abstract]. HEPATOLOGY $1992 ; 16: 51 \mathrm{~A}$

47. Rozga J, Williams F, Ro M-S, Neuzil DF, Giorgio TD, Backfisch G, Moscioni A, et al. Development of a bioartificial liver: properties and function of a hollow-fiber module inoculated with liver cells. HEPATOLOGY 1993; 17:258-265.

48. Rozga J, Podesta L, Le Page E, Hoffman A, Demetriou AA. Control of cerebral oedema by total hepatectomy and extracorporeal liver support in fulminant hepatic failure. Lancet 1993;342:898899

49. Moscioni AD, Roy-Chowdhury J, Barbour R, Bown LL, RoyChowdhury N, Competiello LS, Lahiri P, et al. Human liver cell transplantation: prolonged function in athymic rats. Gastroenterology 1989;96:1546-1551.

50. Moscioni AD, Nanney L, Brown L, Barbour R, Demetriou AA. Transplantation of microcarrier-attached human hepatocytes into Gunn rats. Surg Forum 1987;38:385-387.

51. Demetriou AA, Whiting JF, Feldman D, Levenson SM, RoyChowdhury N, Mosconi AP, Kram M, et al. Replacement of liver function in rat by transplantation of microcarrier-attache hepatocytes. Science 1986;233:1190-1192.

52. Rozga J, Bellew T, Moscioni AD, Demetriou AA. Transplantation of microencapsulated hepatocytes into analbuminemic rats. Surg Forum 1991; 42:419-421.

53. Roy-Chowdhury J, Grossman M, Gupta S, Roy-Chowdhury N, Baker JR, Wilson JM. Long-term improvement of hypercholesterolemia after ex vivo gene therapy in LDLR-deficient rabbits. Science 1991;254:1802-1805.

54. Grossman M, Wilson JM. Frontiers in gene therapy: LDL receptor replacement for hypercholesterolemia. J Lab Clin Med $1992 ; 119: 457-460$.

55. Demetriou AA, Reisner A, Sanchez J, Levenson SM, Moscioni AD, Roy-Chowdhury J. Transplantation of microcarrierattached hepatocytes into $90 \%$ partially hepatectomized rats. HEPATOLOGY 1988;8:1006-1009.
56. Levin $\mathrm{S}, \mathrm{Hahn} \mathrm{T}$. Interferon system in acute viral hepatitis. Lancet 1982;1:592-595.

57. Sanchez-Tapias JM, Mas A, Costa J, Bruguera M, Mayor A, Ballesta AM, Compernolle C, et al. Recombinant alpha-2c interferon therapy in fulminant viral hepatitis. J Hepatol 1987; 5:205210.

58. Tassapoulos NC, Hadziyannis SJ, Wright GE. Recombinant human interferon alfa-2b in the management of acute type B hepatitis [Abstract]. HePATOLOGY 1989;10:576.

59. Decker K. Eicosanoids, signal molecules of liver cells. Semin Liver Dis 1985;5:175-190.

60. Noda Y, Hughs RD, Williams R. Effect of prostacyclin $\left(\mathrm{PGI}_{2}\right)$ and a prostaglandin analogue $\mathrm{BW} 245 \mathrm{C}$ on galactosamine-induced hepatic necrosis. J Hepatol 1986;2:53-64.

61. Abecassis M, Falk JA, Makowka L, Dindzans VJ, Falk RE, Levy GA. 16,16-dimethyl prostaglandin $\mathrm{E}_{2}$ prevents the development of fulminant hepatitis and blocks the induction of monocyte/macrophage procoagulant activity after murine hepatitis virus strain 3 infection. J Clin Invest 1987;80:881-889.

62. Sinclair SB, Greig PD, Blendis LM, Abecassis M, Roberts EA, Phillips MJ, Cameron R, et al. Biochemical and clinical response of fulminant viral hepatitis to administration of prostaglandin E: a preliminary report. J Clin Invest $1989 ; 84: 1063-1069$.

63. Bernuau J, Babany G, Bezeaud A, Samuel D, Cereda JM, Erlinger S, Benhamou JP. Does prostaglandin E1 (PGE1) prevent further aggravation in severe, or early fulminant hepatitis? A preliminary open trial [Abstract]. J Hepatol 1989; 9(suppl):S114.

64. Sheiner P, Sinclair S, Greig P, Logan A, Blendis LM, Levy G. A randomized control trial of prostaglandin $\mathrm{E}_{2}$ in the treatment of fulminant hepatic failure [Abstract]. HEPATOLOGY 1992;16:88A.

65. Fox IJ, Langnas AN, Ozaki CF, Byonon JS, Vogel J, Fristoe L, Merrill J, et al. Successful application of extracorporeal liver perfusion for the treatment of fulminant hepatitis failure: a technology whose time has come. Am J Gastroentrol 1993;88:18761881.

66. Fair J, Maley W, Stephenson R, Kittur D, Wiener C, Klein A. Extracorporeal porcine liver perfusion as a successful bridge to orthotopic liver transplantation (OLT) [Abstract]. Gastroenterology $1993 ; 104: 899 \mathrm{~A}$.

67. Chari RS, Collings BH, Magee JC, DiMaio JM, Kirk AD, Harland RC, McCann RL, et al. Brief report: treatment of hepatic failure with ex vivo pig-liver perfusion followed by liver transplantation. N Engl J Med 1994;331:234-237.

68. Reemtsma K, McCracken BH, Schlegel JU. Renal hetero-transplantation in man. Ann Surg 1964: 160:384-408.

69. Bailey LL, Nehlsen-Cannarella SL, Concepcioun W, Jolley WB. Baboon to human cardiac xenotransplantation in a neonate. JAMA 1985;254:3321-3329.

70. Murase N, Starzl TE, Demetris AJ, Valdivia L, Tanabe M, Cramer D, Makowka L. Hamster to rat heart and liver xenotransplantation with FK506 plus anti-proliferative drugs. Transplantation 1993;55:701-707.

71. Rozga J, Podesta L, Le Page E, Hoffman A, Morsiani E, Sher L, Woolf GM, et al. Control of cerebral edema by total hepatectomy and extracorporeal liver support in fulminant hepatic failure. Lancet 1993;342:898-899.

72. Abouna GM, Fischer LM, Porter KA, Andres G. Experience in the treatment of hepatic failure by intermittent liver hemo-perfusions. Surg Gynecol Obstet 1973;137:741-752.

73. Starzl TE, Fung J, Tzakis A, Todo S, Demetris AJ, Marino IR, Doyle $\mathrm{H}$, et al. Baboon-to-human liver transplantation. Lancet $1993 ; 341: 65-71$.

74. Todo S, Demetris AJ, Van Thiel D, Fung JJ, Starzl TE. Orthotopic liver transplantation for patients with hepatitis B virus related liver disease. HePATOLOGY 1991;13:619-626.

75. Chiche L, Adam R, Caillat-Zucman S, Castaing D, Bach JF, Bismuth $\mathrm{H}$. Xenotransplantation: baboons as potential liver donors? Scientific and ethical issues. Transplantation 1993; $55: 1418-1421$ 